\title{
Prevalence and Factors Influencing Alcohol Use in Pregnancy among Women Attending Antenatal Care in Dodoma Region, Tanzania: A Cross-Sectional Study
}

\author{
Matunga Mpelo, ${ }^{1}$ Stephen Matthew Kibusi $\left(\mathbb{D},{ }^{1}\right.$ Fabiola Moshi ${ }^{D},{ }^{1}$ Azan Nyundo $\left(\mathbb{D},{ }^{2}\right.$ \\ Julius Edward Ntwenya, ${ }^{1}$ and Bonaventura C. T. Mpondo $\mathbb{D}^{2}$ \\ ${ }^{1}$ School of Nursing and Public Health, College of Health Sciences, The University of Dodoma, Dodoma, Tanzania \\ ${ }^{2}$ School of Medicine and Dentistry, College of Health Sciences, The University of Dodoma, Dodoma, Tanzania \\ Correspondence should be addressed to Stephen Matthew Kibusi; skibusi@gmail.com
}

Received 29 April 2018; Revised 19 September 2018; Accepted 26 September 2018; Published 18 October 2018

Academic Editor: Luca Marozio

Copyright (c) 2018 Matunga Mpelo et al. This is an open access article distributed under the Creative Commons Attribution License, which permits unrestricted use, distribution, and reproduction in any medium, provided the original work is properly cited.

Background. Alcohol use during pregnancy is high despite the well-established evidence on its adverse pregnancy outcomes and poor child development. Early identification and behavioural modification are of great significance. This study aimed to determine the prevalence and associated factors of alcohol use during pregnancy among women in Dodoma region. Methods. 365 randomly selected pregnant women attending antenatal care services in Dodoma region were included. Structured questionnaires were used to assess sociodemographic characteristic and alcohol use. Both descriptive and inferential analyses were used to estimate the prevalence and independent relationships of factors associated with alcohol use in pregnancy, respectively. Results. Results showed a prevalence of $15.1 \%$ out of the 365 women attending antenatal services in Dodoma region. Prepregnancy alcohol use and having relatives who use alcohol were associated with alcohol use (AOR= 5.19; 95\% CI: 4.791-34.867 and AOR=1.57; 95\% CI: 1.3936.248), respectively. Moreover, other associated factors included low education status (AOR=10.636; 95\% CI: 1.89-19.844), making local brews as a source of income (AOR=11.44; 95\% CI: 1.008-19.86), and not having had complications in previous pregnancies $(\mathrm{AOR}=4.93 ; 95 \% \mathrm{CI}$ : 1.031-23.59). Conclusion. There is a significantly high prevalence of alcohol use during pregnancy in Dodoma. Social networks and low social, economic status were associated with alcohol use in pregnancy. There is a need for public health interventions to address alcohol use particularly targeting women of reproductive age with low socioeconomic status.

\section{Introduction}

Alcohol use during pregnancy has been confirmed for many years to be associated with negative effects on the mother and unborn child. The effect of alcohol use during pregnancy is evident immediately after birth, during early or later life particularly when it damages the Central Nervous System (CNS). Limiting the exposure to alcohol is one of the modifiable risk factors for poor pregnancy outcomes [1-4].

Binge or heavy drinking (defined as five or more drinks per occasion) is associated with Fetal Alcohol Spectrum Disorders (FASD), a more severe effect. Fetal alcohol syndrome (FAS) causes both prenatal and postnatal growth deficiency. Moreover, alcohol has been reported to be the cause of low birth rate [5-7]. Despite rampant evidence on the effects, studies show that there is an increasing trend in alcohol use during pregnancy in developing countries. In Tanzania, up to $34.1 \%$ of pregnant women have reported experiences of drinking alcohol [3].

Given the increasing prevalence of alcohol use during pregnancy, there is a need for understanding factors predisposing mothers to alcohol use during pregnancy. Previous alcohol use before pregnancy, social status, higher incomes, tobacco use, partner violence, having partners or friends who drink, late pregnancy recognition, and perceived alcohol risks had been associated with alcohol use in pregnancy. Others include traumatic history, employment, and educational status. In Tanzania availability and affordability of alcohol, maternal age, parity, religion affiliation, tribe, and HIV status contribute to high prevalence of alcohol use [8-15]. 
Although there is uncertainty regarding the safe level for drinking during pregnancy, research findings appear to signal that abstinence is probably the safest option. In Tanzania all antenatal care services including those located in Dodoma region recommend women to abstain from drinking during pregnancy. So this study was set to determine prevalence and factors influencing alcohol use among pregnant women in the Dodoma region.

\section{Methods}

It was a descriptive cross-sectional study which included 365 pregnant women attending antenatal care services. The study was conducted in Dodoma region the capital city of Tanzania. Dodoma region lies in the eastern-central part of the country. As per 2012 census, the region had a population of 2,083,588 [16]. It is among the least developed area of Tanzania with the highest maternal/child death rates, the majority $(80 \%)$ of the Dodoma population lives in rural areas and continuously threatened by famine, and they are accustomed to engaging into drinking behaviour during agricultural off season [2]. The region is divided into seven districts, namely, Dodoma Urban, Kondoa, Mpwapwa, Chemba, Bahi, and Chamwinoand Kongwa.

2.1. Sample Size and Sampling Technique. A minimum sample of 332 was calculated from Cochrane formula $=\mathbf{Z}^{2} \mathbf{P q} / \mathbf{e}^{2}$, where $\mathrm{Z}$ is standard normal deviate, $\mathrm{P}$ is proportion in the target population, $\mathrm{q}$ is $1-\mathrm{p}$ (proportion in the target population), and e is precision level.

A multiple stage sampling technique was used to select the sample. Among the seven districts, Dodoma Urban and Chamwino districts were purposively chosen due to their high population of women and to ensure representation. Then three health facilities from each district were selected purposively by considering those with more number of women in rural and urban, respectively. Subjects were selected randomly from the list of registration for the specific day.

2.2. Data Collection Procedure. Sociodemographic, pregnancy, and alcohol use information including age, tribe, marital status, level of education, source of income, personal hobbies, membership to the social organization, prepregnancy alcohol use, partner's alcohol use place, sharing drinking with partner, relative or relative or friend using alcohol, gestation age, pregnancy plan, pregnancy recognition, and parity status were considered as predictors of alcohol use during pregnancy and were collected using researcher's designed instrument.

Alcohol use was assessed using WHO Alcohol Use Disorders Identification Test (AUDIT). The tool is the three questions assessment tool for quick assessment of how much (quantity) and how often (frequency) an individual is drinking. Each question has the score from 0 to 4 , and the total score of the tool is 12 . The total score categorises the individual as low-risk drinking (0-3), moderate risk drinking (4-5), and high risk drinking ( $\geq 6)$.
2.3. Data Analysis. The analysis was done by using Statistical Product and Service Solution (SPSS) computer program version 21 which was developed by IBM-Incorporation in 2012. Descriptive statistics were summarized into frequencies and proportions. The factors associated with alcohol consumption in pregnancy were first computed by Chi-square test and variables that reached the statistically significant level of $\mathrm{P} \leq 0.05$ were further modeled into the multiple logistic regression analysis.

\section{Results}

3.1. Description of the Participants. Of all 365 pregnant women with age ranging between 15 and 44 years, the mean age was $26.02 \pm 6.0$, with $15 \%$ of the surveyed population being below 20 years of age and $2.7 \%$ being above 40 years of age. The majority of the participants (78.9\%) were married, and Gogo was the predominant tribe with $(70.1 \%)$ of the participants. The majority $(64.1 \%)$ of the participants' attained maximum of primary level education and $90.1 \%$ were unemployed (Table 1).

As for the reproductive profile, the majority of the participants had at least one previous pregnancy, and $81.9 \%$ were in the second trimester of the index pregnancy (Table 2)

Up to $15.1 \%$ of the participants in this study reported having consumed alcohol in the index pregnancy. Educational status $\left(X^{2}, p<0.001\right)$, the source of income $\left(X^{2}, p<0.05\right)$, type of hobbies $\left(\mathrm{X}^{2}, \mathrm{p}<0.001\right)$, prepregnancy alcohol use $\left(\mathrm{X}^{2}, \mathrm{p}<0.001\right)$, having a partner $\left(\mathrm{X}^{2}, \mathrm{p}<0.001\right)$, a friend $\left(\mathrm{X}^{2}\right.$, $\mathrm{p}<0.001)$, or a relative $\left(\mathrm{X}^{2}, \mathrm{p}<0.001\right)$, sharing of drinks $\left(\mathrm{X}^{2}\right.$, $\mathrm{p}<0.001)$, and preferred place for drinking $\left(\mathrm{X}^{2}, \mathrm{p}<0.001\right)$ with a partner and having had a history of complications in previous pregnancy $\left(\mathrm{X}^{2}, \mathrm{p}<0.001\right)$ were all significantly associated with alcohol consumption during pregnancy (Table 3 ).

Factors significantly associated with alcohol use included educational status (AOR 10.636, 95\% Cl 1.890-19.844, $\mathrm{p}=0.002$ ), making local brews as a source of income as compared with those in small business (AOR $11.44495 \% \mathrm{Cl}$ 1.008-19.861 $\mathrm{p}=0.04)$, prepregnancy alcohol use (AOR, 5.19, $\mathrm{Cl}(4.791-34.867) \mathrm{p}=0.003)$ having relatives who use alcohol (AOR 1.57 95\% Cl 1.393-6.248 p=0.001), and not having had complications in previous pregnancies (AOR $4.9395 \% \mathrm{Cl}$ 1.031-23.590 $\mathrm{p}=0.0046)$ (Table 4).

\section{Discussion}

This study aimed to determine the prevalence and risk factors of alcohol use among pregnant women attending antenatal care services. The findings revealed that about $15.1 \%$ of women consumed alcohol during pregnancy and this consumption was significantly associated with educational status, prepregnancy alcohol use, a source of income, having relatives drinking alcohol, and experiencing complications in the previous pregnancies.

The current study managed to establish a prevalence of $15.1 \%$ using standardized tools to assess alcohol use among pregnant women. This seems to be lower than the proportion of $21.5 \%$ reported in Northern Tanzania in year 2010 also lower than the observation from other African studies where 
TABLE 1: Participants' distribution by sociodemographic and reproductive profile $(n=365)$.

\begin{tabular}{|c|c|c|}
\hline Variable & Frequency & Percentage (\%) \\
\hline \multicolumn{3}{|l|}{ Age group } \\
\hline $15-19$ & 54 & 14.8 \\
\hline $20-24$ & 106 & 29 \\
\hline $25-29$ & 105 & 28.8 \\
\hline $30-34$ & 63 & 17.3 \\
\hline $35-39$ & 27 & 7.4 \\
\hline $40+$ & 10 & 2.7 \\
\hline \multicolumn{3}{|l|}{ Tribe } \\
\hline Gogo & 256 & 70.1 \\
\hline Rangi & 26 & 7.1 \\
\hline Others & 83 & 22.7 \\
\hline \multicolumn{3}{|l|}{ Marital status } \\
\hline Single & 32 & 8.8 \\
\hline Married & 288 & 78.9 \\
\hline Cohabiting & 45 & 12.3 \\
\hline \multicolumn{3}{|l|}{ Educational status } \\
\hline$\leq$ Primary education & 303 & 83 \\
\hline Post-primary education & 62 & 17 \\
\hline \multicolumn{3}{|l|}{ Employment status } \\
\hline Employed & 17 & 4.7 \\
\hline Unemployed & 329 & 90.1 \\
\hline Self-employed & 19 & 5.2 \\
\hline \multicolumn{3}{|l|}{ Participant's hobbies } \\
\hline Making stories with friends & 113 & 31 \\
\hline Watch Television/listen to Radio & 150 & 41.1 \\
\hline Music (singing or dancing) & 102 & 27.9 \\
\hline
\end{tabular}

TABLE 2: Participants' distribution by reproductive profile $(n=365)$.

\begin{tabular}{lcc}
\hline Variable & Frequency & Percent (\%) \\
\hline Parity status & & \\
0 & 106 & 29 \\
1 to 2 & 150 & 41.1 \\
$\geq 3$ & 109 & 29.9 \\
Gestation age & & \\
First trimester & 66 & 18.1 \\
Second trimester & 299 & 81.9 \\
Complication in previous pregnancies & & \\
Yes & 33 & 9 \\
No & 332 & 91 \\
Pregnancy plan of the participant & & \\
Planned & 195 & 53.4 \\
Unplanned & 170 & 46.6 \\
\hline
\end{tabular}

the prevalence ranged from $30 \%$ to $59.2 \%$ [3-6] but somewhat higher than the prevalence reported in developed countries such as Sweden and Canada with prevalence of $12 \%$ and $10.8 \%$, respectively $[7,8]$. The difference on the prevalence between this study and the study from Northern Tanzania may partly be explained by the differences in methodology, as this was a cross-sectional design which interviewed women from the antenatal clinic while the Northern Tanzania study was a registry-based survey. This study has shown that higher education level is associated with alcohol use during pregnancy. This observation is consistent with results found in Ethiopia, Sweden and Japan [10-12]. However, in countries such as Spain, higher education is among the factors influencing alcohol cessation during pregnancy [13]. Although it was expected that women with higher education would be aware of the risk of drinking during pregnancy this study found a positive relationship; this gives the reason for further research to examine the association between alcohol use during pregnancy and educational status.

This study also found that prepregnancy alcohol use predicts drinking during pregnancy. This is consistent with to date literature that alcohol use before pregnancy is the best predictor of drinking during pregnancy [11, 14, 15]. Alcohol produces a physiological effect such as the strong desire to consume despite knowing the outcomes [17]; thus when an individual has drinking tendency this becomes a habit that is difficult to break [18] or one may develop withdrawal symptoms that make abstinence difficult even after conceiving. Possibly most of the women with alcohol prepregnancy do experience withdrawal symptoms that make difficult for them to stop abruptly after becoming pregnant.

Having relatives with drinking behaviour has been associated with drinking during pregnancy in this study. Thus 
TABLE 3: Factors associated with alcohol use among pregnant women attending Reproductive and Child Health (RCH) clinic in Dodoma using chi-square $(n=365)$.

\begin{tabular}{|c|c|c|c|c|}
\hline \multirow{2}{*}{ Variable } & \multicolumn{4}{|c|}{ Ever drank in the index pregnancy } \\
\hline & Yes & No & $\mathrm{X} 2$ & P-value \\
\hline \multicolumn{5}{|l|}{ Educational status } \\
\hline$\leq$ Primary education & $43(14.2)$ & $250(85.6)$ & & \\
\hline Post-primary education & $12(19.4)$ & $60(80.8)$ & 34.98 & 0.000 \\
\hline \multicolumn{5}{|l|}{ Source of income } \\
\hline Small business & $21(13.0)$ & $141(87.0)$ & & \\
\hline Farming & $28(14.8)$ & $161(85.2)$ & 8.2 & 0.045 \\
\hline Making local brews & $6(42.9)$ & $8(57.1)$ & & \\
\hline \multicolumn{5}{|l|}{ Participant's hobbies } \\
\hline Making stories & $27(23.9)$ & $86(76.1)$ & & \\
\hline Television/ radio & $11(7.3)$ & $139(92.7)$ & 23.238 & 0.000 \\
\hline Music (sing/ dancing & $17(16.7$ & $85(83.3)$ & & \\
\hline \multicolumn{5}{|c|}{ Pre-pregnancy alcohol use (6 months) } \\
\hline Yes & $47(70.1)$ & $20(29.9)$ & & \\
\hline No & $8(2.7)$ & $290(97.3)$ & 194.5 & 0.000 \\
\hline \multicolumn{5}{|l|}{ Partner drinking alcohol } \\
\hline Yes & $37(28.7)$ & $92(71.3)$ & & \\
\hline No & $18(7.6)$ & $218(92.4)$ & 26.9 & 0.000 \\
\hline \multicolumn{5}{|l|}{ Partner drinking place } \\
\hline At home & $12(44.4)$ & $15(55.6)$ & & \\
\hline Outside home & $25(22.7)$ & $85(77.3)$ & 28.9 & 0.000 \\
\hline never drinks & $18(7.9)$ & $210(92.1)$ & & \\
\hline \multicolumn{5}{|l|}{ Drinking with husband } \\
\hline Yes & $22(61.1)$ & $14(38.9)$ & & \\
\hline No & $33(10.0)$ & $296(90.0)$ & 66.158 & 0.000 \\
\hline \multicolumn{5}{|l|}{ Friends using alcohol } \\
\hline Yes & $40(28.8)$ & $99(71.2)$ & & \\
\hline No & $15(6.6)$ & $211(93.4)$ & 32.96 & 0.000 \\
\hline \multicolumn{5}{|l|}{ Relatives using alcohol } \\
\hline Yes & $46(26.0)$ & $131(74.0)$ & & \\
\hline No & $9(4.8)$ & $179(95.2)$ & 32.02 & 0.000 \\
\hline \multicolumn{5}{|c|}{ Previous pregnancies complications } \\
\hline Yes & $12(36.4)$ & $21(63.6)$ & & \\
\hline No & $43(13.0)$ & $289(87.0)$ & 12.856 & 0.001 \\
\hline \multicolumn{5}{|l|}{ Pregnancy plan } \\
\hline Planned & $22(11.3)$ & $17(88.7)$ & 4.69 & 0.0039 \\
\hline Unplanned & $33(19.4)$ & $137(80.6)$ & & \\
\hline
\end{tabular}

women whose partner and relatives use alcohol are more likely to drink during pregnancy. This is consistent with findings from previous studies; one study revealed that women admitted they would be less likely to drink if their partner and relatives stopped from drinking during pregnancy period [15]. In African countries south of Sahara male partner drinking behaviour is among the risk factor for women to drink alcohol during pregnancy [19]. This might be because relatives plays a role as an essential role model for an individual to decide to drink and sometimes one can be invited to drink alcohol and becomes difficult for her to resist.
Besides, this study found that making local alcohol as the source of income increased the likelihood of consuming alcohol during pregnancy. Making and selling traditionally made alcohol increase the access since the women can take in the house which appears to be at ease place for them to drink alcohol [20]. Women who had never experienced complications in the previous pregnancy were more likely to use alcohol in the index pregnancy. However, some studies have shown that there is no association between alcohol consumption during pregnancy and previous pregnancy complications [10]. This can be explained as women who have 
TABLE 4: Factors associated with alcohol use among pregnant women attending Reproductive and Child Health (RCH) clinic in Dodoma region $(\mathrm{n}=365)$.

\begin{tabular}{|c|c|c|c|c|}
\hline Variable & OR $(95 \% \mathrm{CL})$ & P-value & AOR $(95 \% \mathrm{CL})$ & P-Value \\
\hline \multicolumn{5}{|l|}{ Educational status } \\
\hline$\leq$ Primary education & 1 & & 1 & \\
\hline Post- primary education & $2.367(1.065-5.262)$ & 0.000 & $10.636(1.890-19.844)$ & 0.002 \\
\hline \multicolumn{5}{|l|}{ Source of income } \\
\hline Small business & 1 & & 1 & \\
\hline Farming & $1.168(0.635-2.148)$ & & $2.485(0.651-9.020)$ & \\
\hline Making local brews & $5.036(1.589-15.96)$ & 0.049 & $11.444(1.008-19.86)$ & 0.04 \\
\hline \multicolumn{5}{|l|}{ Participant's hobbies } \\
\hline Music & 1 & & 1 & \\
\hline Making stories & $1.570(0.798-3.089)$ & & $2.547(0.651-9.969$ & \\
\hline Watch $\mathrm{Tv} /$ listen to radio & $0.396(0.177-0.885)$ & 0.040 & $0.172(0.031-0.945)$ & \\
\hline \multicolumn{5}{|c|}{ Pre-preg alcohol use (6 months) } \\
\hline No & 1 & & 1 & \\
\hline Yes & $8.519(3.55-20.45)$ & 0.000 & $5.19(4.791-34.867)$ & 0.003 \\
\hline \multicolumn{5}{|l|}{ Partner use of alcohol } \\
\hline No & 1 & & 1 & \\
\hline Yes & $4.871(2.637-8.997)$ & 0.000 & $17.176(0.001-526.0)$ & \\
\hline \multicolumn{5}{|l|}{ Partner drinking place } \\
\hline Never drinks & 1 & & 1 & \\
\hline At home & $8.978(3.653-22.065)$ & 0.000 & $0.012(0.00-38.9614)$ & \\
\hline Outside home & $3.301(1.712-6.365)$ & 0.000 & $0.003(0.00-8.60196)$ & \\
\hline \multicolumn{5}{|c|}{ Share drinking with husband } \\
\hline No & 1 & & 1 & \\
\hline Yes & $14.095(6.58-30.15)$ & 0.000 & $0.977(0.202-4.729)$ & \\
\hline \multicolumn{5}{|l|}{ Friends using alcohol } \\
\hline No & 1 & & 1 & \\
\hline Yes & $5.684(2.998-10.775)$ & 0.000 & $1.389(0.408-4.729)$ & \\
\hline \multicolumn{5}{|l|}{ Relatives using alcohol } \\
\hline No & 1 & & 1 & \\
\hline Yes & $6.984(3.302-14.771)$ & 0.000 & $15.662(1.393-6.248)$ & 0.001 \\
\hline \multicolumn{5}{|c|}{ Complications in previous pregnancies } \\
\hline Yes & 1 & & 1 & \\
\hline No & $3.841(1.764-8.363)$ & 0 & $4.932(1.031-23.590)$ & 0.0046 \\
\hline \multicolumn{5}{|l|}{ Pregnancy plan } \\
\hline Planned & 1 & & 1 & \\
\hline Unplanned & $1.894(1.056-3.397)$ & 0.02 & $0.938(0.288-3.056)$ & \\
\hline
\end{tabular}

never experienced any difficulty is easier for them to drag into risky behaviour like alcohol use.

\section{Conclusions}

The study findings revealed that alcohol use was common during pregnancy in Dodoma region. The predisposing factors for alcohol use during pregnancy were shown to be being using alcohol before pregnancy, having a relative who is using alcohol, making local brews as the source of income and experience of getting complication with alcohol use in previous pregnancies. Interventional studies are needed to come up with an effective strategy to reduce the prevalence of alcohol use during pregnancy.

\section{Data Availability}

The data used to support the findings of this study are available from the corresponding author upon request.

\section{Ethical Approval}

The protocol and data collection procedures for this study were approved by the University of Dodoma Ethical Review Board. Permission to conduct the research was obtained from the office of the Dodoma Regional Administrative Secretary (RAS) through the office of the Regional Medical Officer. Letters of approval were submitted to the District and Facility Authorities before the beginning of the study. Interviews 
were conducted under the most private conditions afforded at the Antenatal Care Centers. After the interviews, health education was provided to the participants on the effect of alcohol use during pregnancy, with those who reported the use of alcohol in current pregnancy recruited in a BRIEF interventional study that aimed at reversing their drinking behaviour.

\section{Consent}

All participants were asked to provide written informed consent after reading a document emphasizing the voluntary nature of the survey. Verbal consent was requested from guardians (mostly mothers/sisters/mother-in-law) of pregnant women under the age of 18 years before getting their accent to participate in the study.

\section{Disclosure}

The authors have indicated that they have no financial relationship relevant to this manuscript to disclose. The study was conducted as part of the first author's Masters of Science in Mental Health Nursing offered at the University of Dodoma, School of Nursing and Public Health.

\section{Conflicts of Interest}

The authors declare that they have no conflicts of interest.

\section{Authors' Contributions}

Matunga Mpelo originated the research question and conceptualisation of the study, review of research instrument, data collection, and analysis as well as writing of the manuscript as part of her M.S. Mental Health Nursing studies at the University of Dodoma. Stephen Matthew Kibusi contributed to the conceptualisation, development, and design of methodology, data Curation, formal analysis, and overall oversight and leadership responsibility for the research activity planning and execution of the study. Azan Nyundo, Julius Edward Ntwenya, and Bonaventura C. T. Mpondo were involved in supervising this work at every step of its development and participated in writing the manuscript. Fabiola Moshi participated in writing and reviewing the manuscript. All authors read and approved the final manuscript.

\section{Acknowledgments}

The authors are grateful for the assistance provided by the Health Care Workers in Antenatal Care Centers involved in this study. Special thanks are due to the participants for their time and readiness to participate in this study.

\section{References}

[1] National Bureau of Statistics, "Mortality and Health," Dar es Salaam, 2015.
[2] F. Kessy, O. Mashindano, D. Rweyemamu, and P. Charle, Poverty Escape Routes in Central Tanzania: Coping Strategies in Singida and Dodoma Regions, 2011.

[3] A. B. Isaksen, T. Østbye, B. T. Mmbaga, and A. K. Daltveit, "Alcohol consumption among pregnant women in Northern Tanzania 2000-2010: a registry-based study," BMC Pregnancy and Childbirth, vol. 15, no. 1, article 205, 2015.

[4] B. Ordinioha and S. Brisibe, "Alcohol consumption among pregnant women attending the ante-natal clinic of a tertiary hospital in South-South Nigeria," Nigerian Journal of Clinical Practice, vol. 18, no. 1, pp. 13-17, 2015.

[5] G. Adeyiga, E. A. Udofia, and A. E. Yawson, "Alcohol and childbearing women, factors associated with alcohol consumption: a survey of women childbearing at a national referral hospital in accra, Ghana," African Journal of Reproductive Health, vol. 18, pp. 152-165, 2014.

[6] Y. Adusi-Poku, A. K. Edusei, A. A. Bonney, H. Tagbor, E. Nakua, and E. Otupiri, "Pregnant women and alcohol use in the Bosomtwe district of the Ashanti region-Ghana," African Journal of Reproductive Health, vol. 16, no. 1, pp. 55-60, 2012.

[7] E. Comasco, G. Hallberg, A. Helander, L. Oreland, and V. Sundelin-Wahlsten, "Alcohol consumption among pregnant women in a swedish sample and its effects on the newborn outcomes," Alcoholism: Clinical and Experimental Research, vol. 36, no. 10, pp. 1779-1786, 2012.

[8] M. J. Walker, B. Al-Sahab, F. Islam, and H. Tamim, “The epidemiology of alcohol utilization during pregnancy: an analysis of the Canadian Maternity Experiences Survey (MES)," BMC Pregnancy and Childbirth, vol. 11, no. 1, article 52, 2011.

[9] R. Gray and J. Henderson, "Review of the fetal effects of prenatal alcohol exposure," Rep to Dep Heal, 2006.

[10] K. Anteab, B. Demtsu, and M. Megra, "Assessment of Prevalence and Associated Factors of Alcohol Use during Pregnancy among the dwellers of Bahir-Dar City Northwest Ethiopia," International Journal of Pharma Sciences and Research (IJPSR), vol. 5, no. 12, pp. 939-946, 2014.

[11] J. Skagerström, S. Alehagen, E. Häggström-Nordin, K. Årestedt, and P. Nilsen, "Prevalence of alcohol use before and during pregnancy and predictors of drinking during pregnancy: a cross sectional study in Sweden," BMC Public Health, vol. 13, no. 1, article 780, 2013.

[12] Y. Yamamoto, Y. Kaneita, E. Yokoyama et al., "Alcohol consumption and abstention among pregnant Japanese women," Journal of Epidemiology, vol. 18, no. 4, pp. 173-182, 2008.

[13] S. Palma, R. Pardo-Crespo, M. Mariscal, R. Perez-Iglesias, J. Llorca, and M. Delgado-Rodríguez, "Weekday but not weekend alcohol consumption before pregnancy influences alcohol cessation during pregnancy," European Journal of Public Health, vol. 17, no. 4, pp. 394-399, 2007.

[14] A. Anderson, A. Hure, P. Forder, J. Powers, F. Kay-Lambkin, and D. Loxton, "Predictors of antenatal alcohol use among Australian women: a prospective cohort study," BJOG: An International Journal of Obstetrics \& Gynaecology, vol. 120, no. 11, pp. 1366-1374, 2013.

[15] E. Peadon, J. Payne, N. Henley et al., "Attitudes and behaviour predict women's intention to drink alcohol during pregnancy: the challenge for health professionals," BMC Public Health, vol. 11 , no. 1, article 584, 2011.

[16] National Bureau of Statistics (NBS), Office of Chief Government Statistician (OCGS). Population Distribution by Age and Sex: The United Republic of Tanzania, 471, 2013, http://ihi .eprints.org/2169/1/Age_Sex_Distribution.pdf. 
[17] J. Rehm, "The risks associated with alcohol use and alcoholism," Alcohol Research and Health, vol. 34, no. 2, pp. 135-143, 2011.

[18] J. Skagerstróm, G. Chang, and P. Nilsen, "Predictors of drinking during pregnancy: A systematic review," Journal of Women's Health, vol. 20, no. 6, pp. 901-913, 2011.

[19] C. L. Culley, T. D. Ramsey, G. Mugyenyi, G. N. Kiwanuka, J. Ngonzi, S. MacLeod et al., "Alcohol exposure among pregnant women in sub-saharan africa: a systematic review," Journal of Population Therapeutics and Clinical Pharmacology, vol. 20, no. 3, pp. 321-333, 2013.

[20] Y. Adusi-Poku, A. A. Bonney, and G. D. Antwi, "Where, when and what type of alcohol do pregnant women drink?" Ghana Medical Journal, vol. 47, no. 1, pp. 35-39, 2013. 


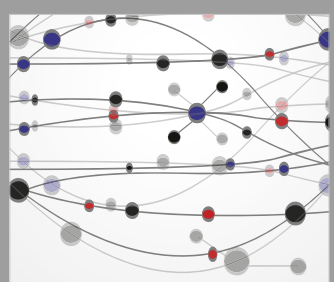

The Scientific World Journal
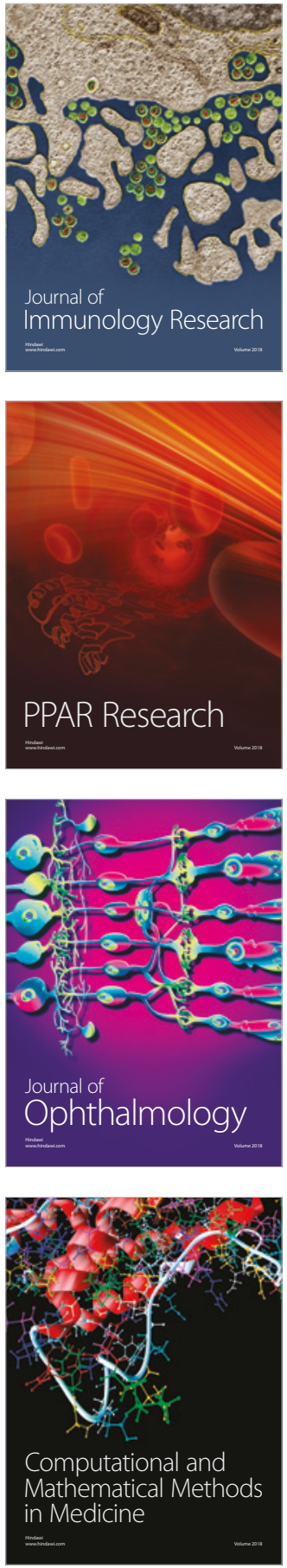

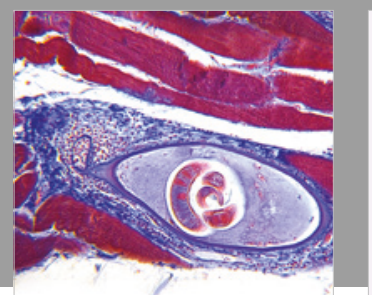

Gastroenterology Research and Practice

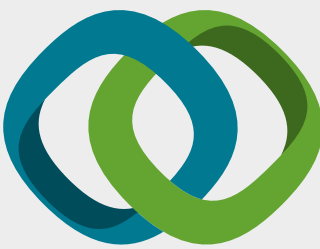

\section{Hindawi}

Submit your manuscripts at

www.hindawi.com
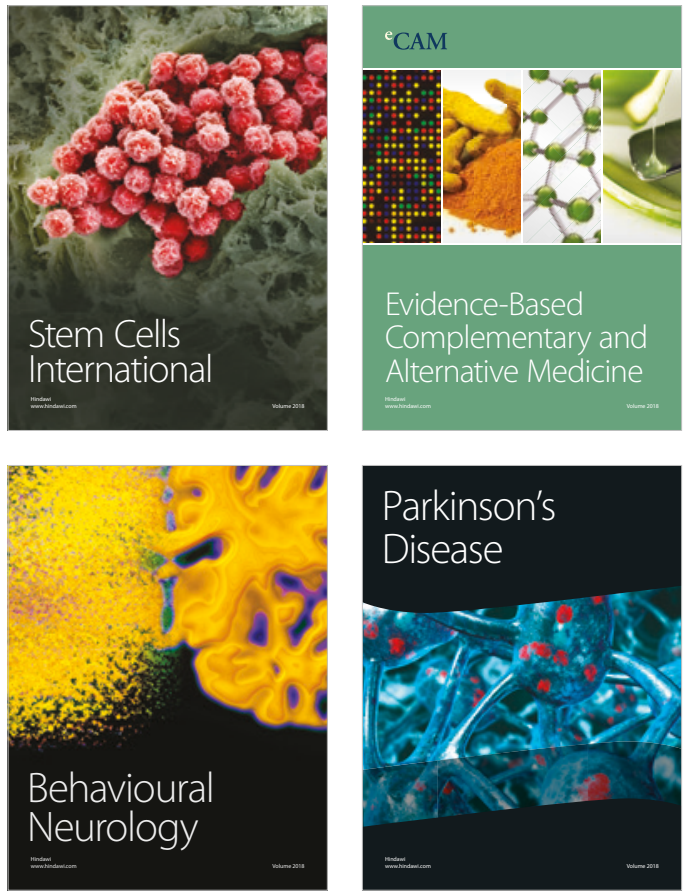

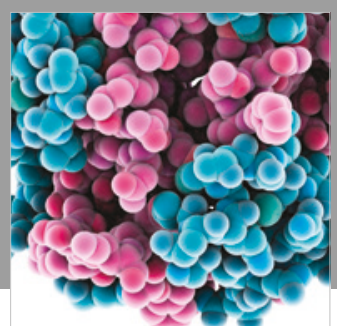

ournal of

Diabetes Research

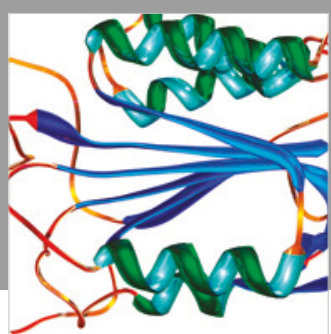

Disease Markers
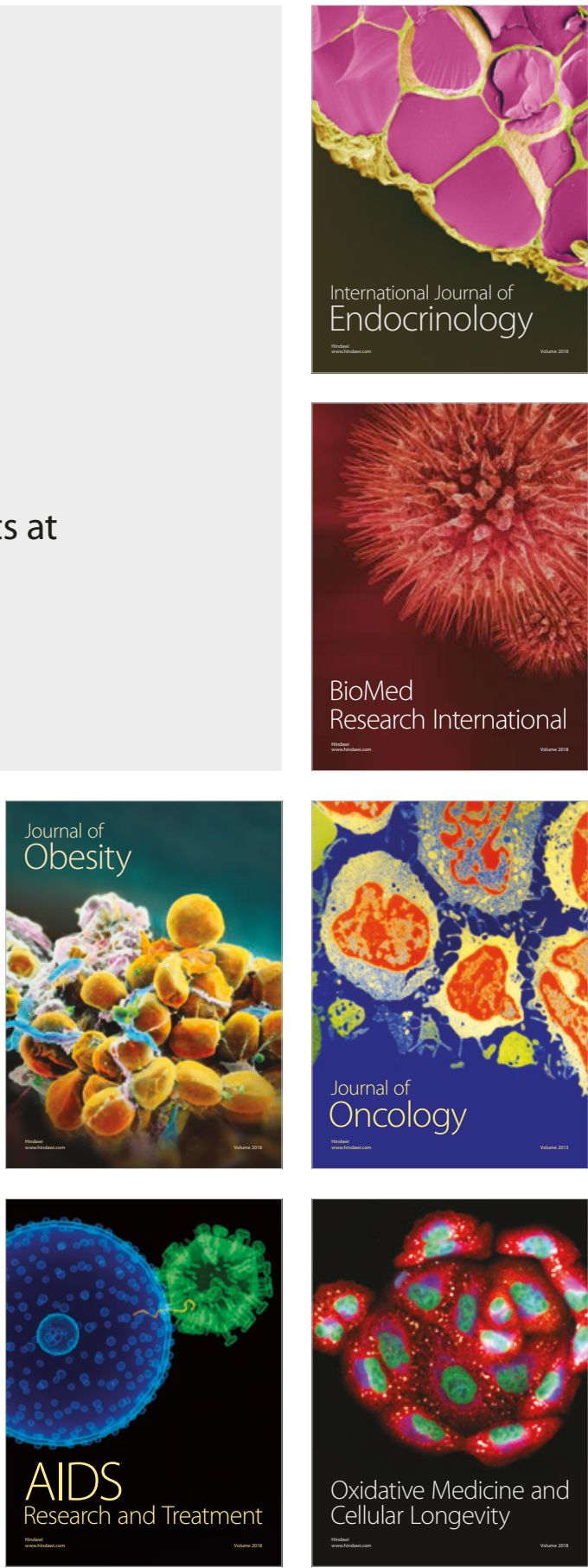